\title{
"Sharing" tourism as an opportunity for territorial regeneration: the case of Iseo Lake, Italy
}

\author{
SARA BELOTTI ${ }^{1}$
}

\begin{abstract}
The spread of sharing economics platforms in the world of travels has highlighted the little known phenomenon of the rental of houses and apartments with a non-enterprise management. These accommodations in Italy do not require any guest registration or start-up notification, but the use of websites such as Airbnb has led to a heated debate among the actors operating in the travel and tourism industry. In fact, the regulatory vacuum and the easy-to-use websites would help circumvent the rules in order to "hide away" some business activities. Based on these assumptions, this paper analyses the case of Iseo Lake in the Northern Italy, pointing out the discussions about this new trend in travels and involving not only economic and legal aspects, but also social issues that cannot be ignored. The paper presents "sharing tourism" as an opportunity for territorial regeneration in destinations characterized by the presence of few hotel facilities, but also of many empty apartments.
\end{abstract}

Keywords: sharing economy, hidden tourism, alternative hospitality, renting houses, peer-to-peer accommodation, Airbnb, territorial regeneration, Iseo Lake

\section{Introduction}

The recent development of sharing economy ${ }^{2}$ in tourism has led to an increased rental of holiday houses on the Internet (Zervas, G. et al. 2017). This fact reflects the need of the owners to occasionally supplement their income and, at the same time, stresses a progressive change of tourism habits and tourists, who prefer short and recurring stays throughout the year directly booked from the Internet, allowing them to authentically experience the place by lodging in facilities managed by locals. With reference to the first point, Karlsson, L. and Dolnicar, S. (2016) conducted an online survey among the Airbnb hosts from Australia to gain insight into what drives the supply side of the peer-to-peer ac- commodation networks, involving all the national active hosts who receive the monthly newsletter. The result of the questionnaires shows that income $(82 \%)$ is main reason for hosting people, followed by social interaction $(31 \%)$ and sharing (14\%) (KARLSSON, L. and Dolnicar, S. 2016). A regards the second point, new low-cost flights also changed the way in which we travel, as well as the dissemination of new ideas at global level, including, for example, sustainable tourism or the Slowfood movement (www.slowfood. com). In this context, holiday houses represent an informal type of accommodation which has recently raised a great interest, reflecting the latest market tendencies such as the growth of holiday farms, guesthouses, shelters and B\&B. Specifically, the paper fo-

\footnotetext{
${ }^{1}$ Università degli Studi di Modena e Reggio Emilia. Dipartimento di Studi Linguistici e Culturali. Largo S. Eufemia, 19. 41121 Modena, Italy. E-mail: sara.belotti@unimore.it

${ }^{2}$ Sharing economy is generally intended as a new economic model. It refers to forms of exchange facilitated through online platforms, encompassing a diversity of for-profit and non-profit activities that are broadly aimed at granting open access to under-utilized resources through what is called "sharing" (RICHARDsON, L. 2015). In addition to vacation rentals, the sharing economy has extended to urban mobility (BÁLINT, D. and TrócsánYI, A. 2017).
} 
cuses on the situation in Lombardy with reference to holiday houses managed in a nonenterprise form only (maximum 3 housing units). In particular, the availability of less than three apartments are considered by the Italian legislation a non-enterprise form, so neither guest registration nor start-up announcement are required. Nowadays this is set, among the business operators of the field, as a major point of discussion seeing the extent at which this lack of regulation would allow, through websites like Airbnb, the law to be circumvented and the actual business activities to be "hidden away".

Now, however, it is necessary to explain how the tourism law works in Italy. On 5 May 2011, the Italian Council of Ministries issued the "Tourism Code" to regulate the tourism sector at State level with the purpose of adapting the existing obligations under the international and EU law. Notwithstanding, at regional level, the Constitution itself (art. 117) assigns exclusive legislative powers to Regions and autonomous Provinces (Trento and Bolzano). Therefore, each Italian Region has its own tourism laws, while, according to the basic principle of subsidiarity, all of them follow the principles set out by the EU and national Italian legislation (http://iftta.org/italy). The Region of Lombardy is an interesting case study, because it has issued a new law that changes the approach to tourist rentals. The old Lombardy Regional Law on Tourism (no. 15 of 16 July 2007) considered holiday houses (case e appartamenti per vacanze - CAV) managed in an enterprise form when the subject had the availability, even temporary, of a minimum of three apartments located in the same municipal territory (art. 43), excluding the cases with less than three apartments (http:// normelombardia.consiglio.regione.lombardia.it). In 2015, the Region approved a new Tourism Law (n. 27/2015) which, for the first time in Italy, tried to legalize the situation of holiday houses managed in a non-enterprise way, defining new procedures in order to hinder tax evasion and unfair competition.

Although this legislation might seem positive at first sight, it is necessary to highlight the complications that this law imposes to those who fairly rent their apartments. In this regard, a discussion is proposed about the consequences arising from the application of this legislation, examining the area of Iseo Lake in Lombardy. This paper stresses how the implementation of the new law cannot be exempted from the analysis of the territorial context, if it aims at promoting the development of a sustainable tourism able to prevent the natural depopulation of small areas. If it is true indeed that spread of the Internet has encouraged new accommodation systems, simultaneously new procedures may disadvantage aged proprietors, most likely found in marginal contexts such as peripheral areas, far from the big cities. In the worst case scenario, such situation may culminate with the dismissal of those accommodations, thus affecting the local development as a whole. To avoid these consequences, the involvement of authorities, tourism associations and citizens, should be promoted to support the creation of a "scattered hospitality". This is defined as a form of tourism characterised by the dispersal of accommodation capacities across an area, based on a network of vocational rentals and holiday houses managed by a central institution that, in this case, may help owners with bureaucratic fulfilments. Scattered tourism should offer new possibilities for revitalising rural areas and include decaying structures in commercial activity, also obtaining funds for their renovation (Burini, F. 2011; Irimiás, A. and Michalkó, G. 2013). For example, in Italy it is worth mentioning the albergo diffuso as defined by DALL'Ara, G. (2015) (www.albergodiffuso.com). This approach can encourage an integrated territory promotion which may turn unused properties into an opportunity.

\section{Holiday houses: definition and diffusion}

Holiday houses reached their peak in Italy in the 1970's and 1980's, although nowadays such phenomenon has reached even higher levels thanks to websites able to connect potential guests with the owners of holiday 
houses, like Airbnb, Booking, Wimdu or HomeAway. Settling down in private accommodations grants an independent management to tourists and meets, at the same time, the economic needs of families, also enabling them to "live like locals" (Romita, T. 2010; Osкam, J. and Boswijk, A. 2016). From a legal point of view, the Italian Tourism Code (art. 53 of Legislative Decree 79/2011) defines holiday houses as those "exclusively rented for tourist purposes, located anywhere", while the Civil Code (art. 1571 et seq.) requires a written and notified agreement only for rentals longer than 30 days. In case of accommodation shorter than 30 days, neither agreements nor fees are required, leaving a legislative void that makes the quantification of this phenomenon much more complicat$\mathrm{ed}^{3}$. Sure enough, the official surveys carried out by the Italian National Institute of Statistics (ISTAT) take into consideration only "classed" facilities (excluding non-enterprise holiday rental) for the estimate of the tourist flow. Considering that this information is only partial, an in-depth analysis is required in order to grasp the whole phenomenon.

According to the ISTAT "Trips and Holidays survey" (Viaggi e Vacanze) ${ }^{4}$, in 2017 there were 291 million overnight stays by Italian tourists in Italy, 98 million of whom chose collective tourism facilities (hotels, specialised collective facilities, other kinds of collective facilities ${ }^{5}$ ). The remaining 193

\footnotetext{
${ }^{3}$ A new tax regime for rentals shorter than 30 days was introduced in Italy only in 2007. It imposes the fulfilment of some tax obligations on those persons who carry out real estate brokerage activities (including telematic portals), such as the withdrawal of the 21 per cent of the income earned by the owners of the accommodation as a flat rate tax, in the event that the broker also takes care of the payment of the accommodation or the tourist tax by the tourist (article 4 and law 96/2017 of Legislative Decree 50/2017).

${ }^{4}$ The survey is conducted on a monthly basis with CAPI (Computer Assisted Personal Interview) technique, on a theoretical national sample of 28,000 households $(7,000$ households per quarter). Since 2014 the survey has been included into the household budget survey (http://dati.istat.it).

${ }^{5}$ The term 'Hotels' includes hotels/motels/boarding houses, religious institutions; 'Specialised collective
}

million people preferred private accommodations, like rented houses/rooms including B\&Bs, personally owned home/timeshare properties, houses of relatives or friends or other private accommodations (ISTAT 2017a). Comparing these data with those collected by Region and Province administrations through official notifications and analysed by the ISTAT 210 million of overnight stays is reached in 2017, 139 million of which were spent in hotels and hotel-tourism residences, while 71 million in other collective accommodations. In particular, more than 18 million people stayed in (rented) holiday dwellings entrepreneurially managed, and more than 3 million people opted for B\&Bs (ISTAT 2017b). Although these data were collected and identified with different methodologies, this comparison allows us to assume the ability of the accommodation facilities (where 210 million overnight stays were spent) to attract the national tourist flow (291 million of overnight stays), amounting to 72 per cent.

Other useful data are provided by the Bank of Italy and were collected through a sample survey at the incoming frontiers of Italy $^{6}$. In 2017, about 368 million foreigner tourists were estimated to come to Italy for an overnight stay (Bank of Italy 2017), of whom 184 million chose a hotel, holiday village, B\&B or holiday farm, while 52 million

\footnotetext{
facilities' are residences for physical/beauty treatment, volunteer work camps and holiday camps, accommodations on means of public transport (couchettes, sleeping cars, etc.), congress and conference centres, holiday farms; 'Other kinds of collective facilities' means holiday villages, campsites, marinas and other collective facilities.

${ }^{6}$ Since 1996 the Bank of Italy has been conducting a comprehensive survey on international tourism for the purpose of calculating the travel item of Italy's monthly balance of payments. Data are collected based on 120,000 interviews at the border points (nearly 70 border points among the most representative ones in terms of flows) with face-to-face interviews using a structured questionnaire. The interviews are conducted at the end of the trip in order to capture the expenditure actually incurred and not the potential or planned one (Survey on International Tourism. Methods and Sources: Methodological Notes. www.bancaditalia.it).
} 
preferred a rented vacation house, more than 62 million opted for another type or facility, nearly 70 million stayed in friends and relatives' houses as guests (VFR). Meanwhile, according to the ISTAT data, 210 million overnight stays by foreigners were recorded both in hotels and in other collective accommodations. Excluding VFRs, there is a big gap between the data provided by the ISTAT and the Bank of Italy, amounting to nearly 88 million. Subject to their pure representative purposes, these statistics show the presence of about 30 per cent of national tourists and nearly 30 per cent of foreign tourists outside the official licensed accommodations, thus assuming that some of them may have benefited from alternative accommodations, including non-enterprise forms of room rentals. In conclusion, the phenomenon of the non-enterprise tourist rental is not negligible, especially considering that the Internet not only favoured the spread of this new type of accommodation but also simplified its procedures and advertisement. This has opened up a new world unknown until now, which needs an in-depth analysis and further research, beyond the financial and legal matters, to examine its territorial effects.

\section{Airbnb: between sharing economy and shadow economy}

Airbnb is one of those websites deriving from the sharing economy which gave a strong impulse to the short-term rental market. Through a free registration, it connects people who have an apartment or a room for rent with those who are looking for temporary accommodations. Service fee amounts to 6 to 12 per cent for guests, and 3 per cent for the landlord, while prices, competitive compared to hotels, are set by users depending on supply and demand. Besides this, Airbnb offers a series of additional services to their users: verified advertisements, payment brokerage, a reciprocity mechanism based on host and guest reputation obtained through reviews. Airbnb's operative system allows only those who offered hospitality and enjoyed it to post first-hand reviews. This helps avoid fake reviews from fake hosts or guests. Furthermore, the organization offers specific services for business travellers (www.airbnb. com). Moreover, Airbnb has recently expanded its supply, going beyond simple home sharing and allowing users to book "experiences" offered by the hosts to get in touch with the local community through cooking classes, guided tours, surf classes and other adventures. Eventually, the "Guidebooks" section offers a collection of all the best places in every city, as suggested by the Airbnb hosts, to discover hidden and one-of-a-kind places.

Despite its relatively recent establishment, in 2008, this new business reality had spread at a quick pace, boasting listings in around 81,000 cities in more than 191 Countries (www.airbnb.com). Italy has gained the third place in the global market, shifting from 52 listings in 2008 to 397,314 at the end of August 2018, with a great impact on the entire national territory at different levels and an exponential growth that shows no signs of stopping $(174,528$ more houses compared to August 2016 with an increase by $78.3 \%$ ) (Federalberghi 2018). In 2017, in Italy there were around 104,000 licensed holiday houses and 19,000 B\&Bs (ISTAT 2017c).

Since the Airbnb system does not help verify which and how many structures are licensed, the comparison between the official data and the number of listings on the website is quite difficult, however, it is possible to highlight the significant extent of this phenomenon size. As already stated, hotel companies have recently criticized Airbnb and other similar websites, accusing them of both encouraging underground profits and supporting shadow economy, together with an unfair competition to the detriment of legally verified tourist structures. In particular, they accuse Airbnb of operating in the interstitial areas of law relying on new and fundamentally different issues not included in statutes and regulations (Kaplant, R.A. and NADLERT, M.L. 2015). 
Internationally speaking, it is worth mentioning the case of Barcelona, Berlin, and San Francisco, where management had "declared war" to Airbnb's illegal rents through heavy fines applied to all the unlicensed apartments (Kendal, M. 2016; Oltermann, B. 2016; Burger, S. 2017). In Italy, in 2017 Federalberghi (the Italian Hotel Association) entrusted the Incipit Consulting society with the monitoring of "hidden" tourism, with a special focus on Airbnb (RÁtz, T. et al. 2015; Minuti, M.S. and Incipit Consulting 2016; Federalberghi 2018). In 2016, Federalberghi estimated 111.4 million tourists located in private houses. Among them, 73.8 million stayed at unlicensed private accommodations, generating a sales volume of 2.4 billion EUR, with 112 million EUR of VAT tax evasion, tourist fees equal to 57 million EUR evaded, 73,000 illegal workers involved who could be turned into regular employees (Intervention recap from Giuseppe Roscioli, Federalberghi vicarial vice-president at the Chamber of Deputies of the Italian Parliament, 2 May 2016). To face this situation, Airbnb has recently defined a community compact in which it declares that it treats every city personally and ensures the payment of its fair share of accommodation and tourist taxes (www.airbnbcitizen.com). Moreover, in the last two years, Airbnb had signed many agreements with cities for the payment of tourist tax. However, the effect caused by this new type of tourism goes well beyond tax or economy, but includes social and territorial issues. For example, many citizens have risen against the increase in rents caused by the presence of Airbnb in urban centres, in spite of the company attempts to promote a responsible home sharing.

From a tourism planning point of view, the lack of official data regarding the measure of the phenomenon makes this issue even more complex, because local administrations base their researches upon official statistic data. Furthermore, the spread of these operative systems and the rental of empty houses could turn out to be favourable for the revitalisation and development of smaller towns, promoting new forms of tourism, in accord- ance with s-Low philosophy, promoting at the same time a territorial regeneration.

\section{Arts and new forms of "micro- accommodation": Iseo Lake towards a new tourist development}

Iseo Lake is the smallest lake at the Alpine foothills (after Como, Garda and Maggiore lakes). Almost equally divided between the Provinces of Bergamo and Brescia, the Lake is characterized by the presence of the largest natural lake island in Italy as well as the of the highest lake island in Europe: Monte Isola, together with two small islands of Loreto and San Paolo (www.visitlakeiseo.info/en/). Fed by the Oglio river, Iseo Lake is located between the Val Camonica to the North (a UNESCO site since 1979 thanks to its prehistoric petroglyphs, http:// whc.unesco.org/en/list/94) and Franciacorta to the South (famous for the production of wine of the same name, www.franciacorta.net/en/).

Lately, it has earned huge global fame thanks to Christo's land art work The Floating Piers which, from 18 June to 3 July 2016, required the installation of three floating piers, covered in a shimmering yellow fabric, that connected the town of Sulzano, on the bank of Brescia, with Monte Isola and then again with the Island of San Paolo, reaching a length of 4.5 kilometres (www.thefloatingpiers.com). This structure, built over the water, aimed at allowing visitors to literally "walk on water", besides giving a new perspective to the lake area. Such event brought to Iseo Lake, in 16 days only, around one million and a half visitors, decisively boosting its tourism promotion. This opportunity strengthens the so-called G16, an association gathering 16 coast municipalities lead by Lovere, offering, for the very first time, an integrated lake tourism promotion.

Thanks to The Floating Piers, moreover, the municipalities received a support from the Lombardy's regional central administration in the form of a loan amounting to 300 million EUR. This money will be invested in communication sharing and the optimisa- 
tion of tourist information points, as well as for the promotion of a Young Artists Factory which assigns areas, natural locations and abandoned buildings to young artists where they can organise workshops and set up temporary art studios, thus appointing the lake as a site of art preserving Christo's legacy. Furthermore, the G16 association, along with Lombardy Region, agreed on a new territorial enhancement plan. Tourism, therefore, is nowadays the core sector in Iseo Lake, but it is essential for this area to be equipped with a network of reception facilities, in order to guarantee its development. Considering the inadequate number of hotels, the lake area is full of B\&Bs and renting locations which, during The Floating Piers days, offered a crucial support to the traditional accommodations. This kind of locally managed "human-sized" hospitality could represent a distinctive feature of the lake territory, also involving empty houses within the tourism chain, as will be explained below.

Airbnb and holidays room-forrent on Iseo Lake

The Iseo Lake accommodation system is characterized by a restricted number of hotels, only 46 among the 16 above-mentioned municipalities, against a high number of B\&Bs and vacation rentals, respectively 52 and $158^{7}$ (Province of Bergamo, Observatory of Tourism 08/31/2016; Province of Brescia, Observatory of Tourism, 06/30/2016). Par-

\footnotetext{
${ }^{7}$ Moreover, there is a hostel in Lovere, and 19 camping sites around the Iseo area.
}

ticularly, in 2015, the holiday rooms for rent were just 17, exponentially increasing within one year, presumably thanks to The Floating Piers event. The vacation rentals were concentrated around the Brescia lake side (Figure 1), within the municipalities of Iseo and Marone at the edge of the restricted area set during the event around Sulzano, where the floating pier started, and Sale Marasino. Bound to their local initiatives, the favourable position and accessibility of these two sites have probably stimulated such proliferation of non-hotel accommodation facilities.

Likewise, in Monte Isola, the core of the event, the peak of the vacation rental was

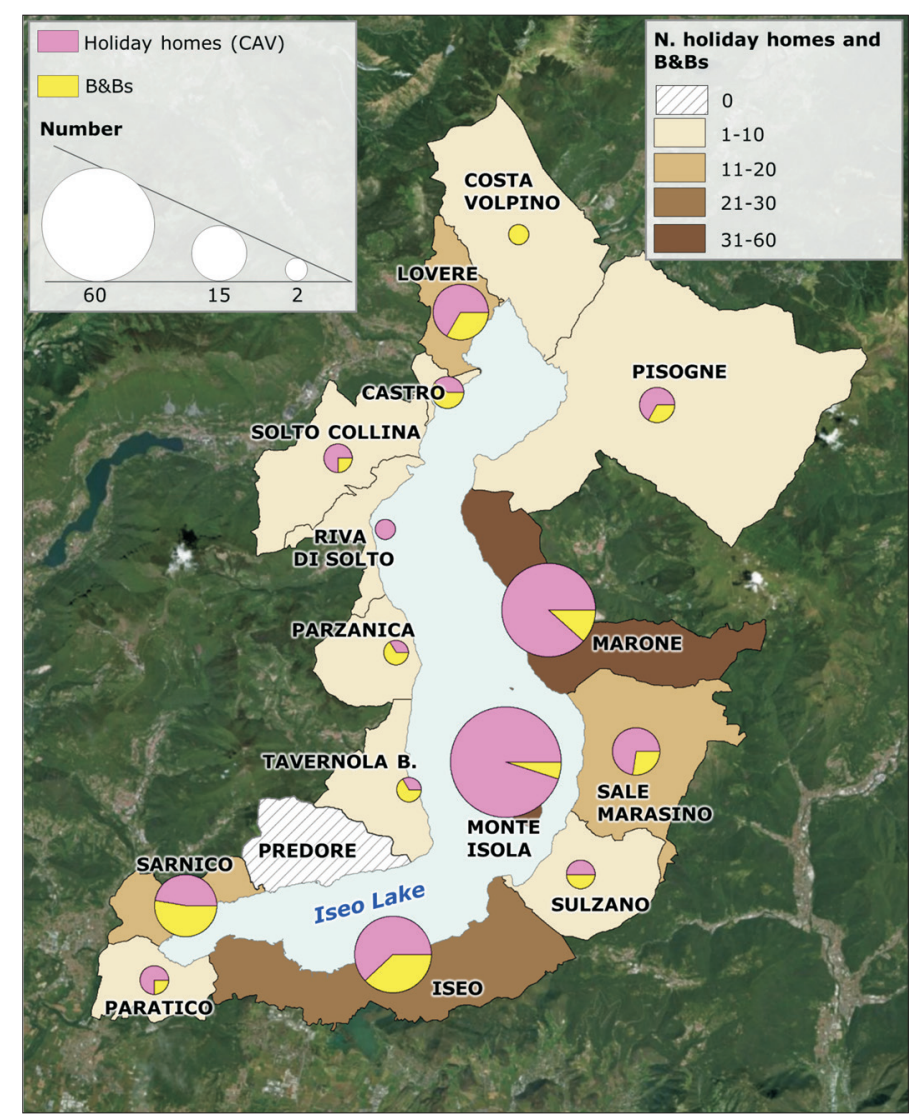

Fig. 1. Territorial distribution of licensed holiday homes and B\&Bs within the G16 municipalities. Data sources: Province of Bergamo, Observatory of Tourism 08/31/2016; Province of Brescia, Observatory of Tourism, $06 / 30 / 2016$. Data processed by the author. 
reached among the first six months of 2016, going from 3 up to 57. In Bergamo lake side, those numbers have diminished, although a considerable increase in the vacation rental is detectable, going from 7 up to 28 in those nine municipalities, while the $\mathrm{B} \& \mathrm{~B}$ data remained unchanged (Province of Bergamo, Observatory of Tourism 08/31/2016). Regarding Airbnb (Figure 2), the advertisements posted by the end of September 2016 were 289, 74 of which concerned rooms for rent, while the remaining 215 referred to entire proprieties.

Analysing the hosts' usernames, a very limited number of people managing more

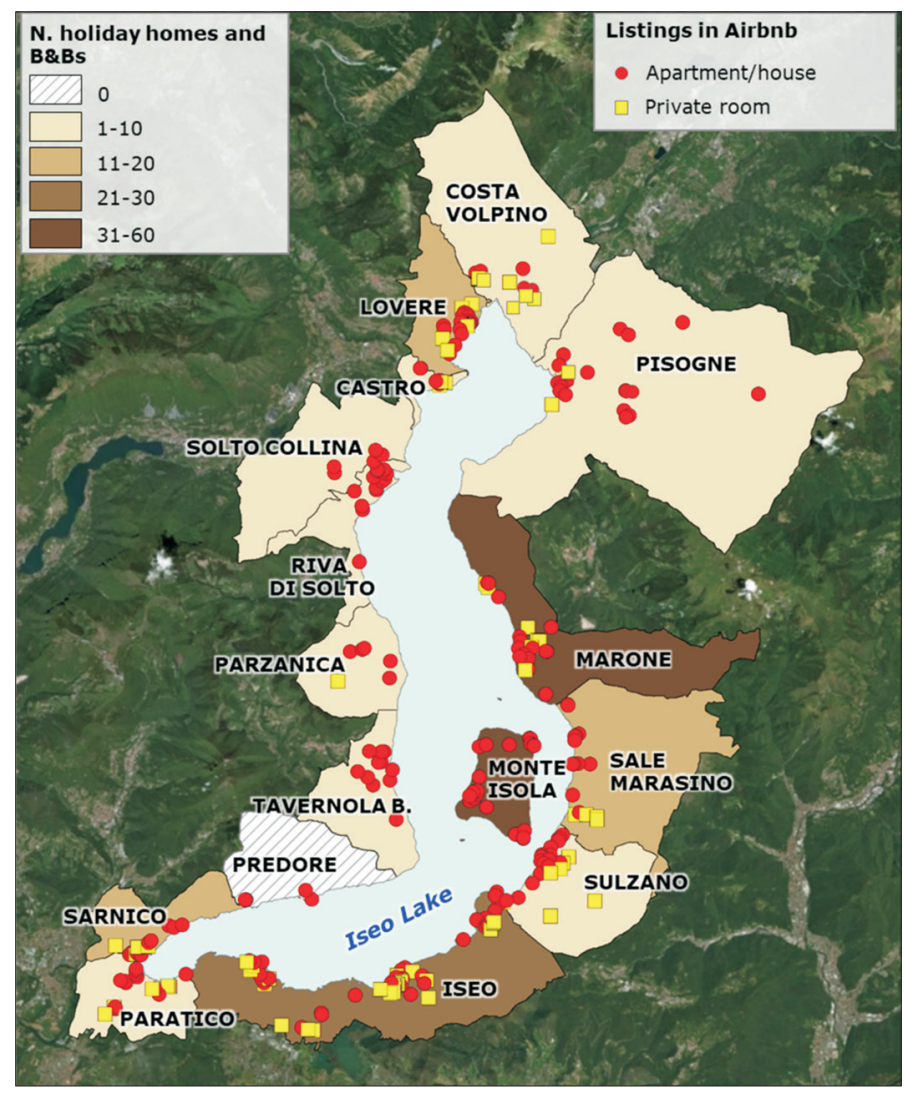

Fig. 2. Spread of Airbnb listings and number of licensed Holiday houses and B\&Bs within the G16 municipalities. Data sources: Province of Bergamo, Observatory of Tourism 08/31/2016; Province of Brescia, Observatory of Tourism, 06/30/2016; www.airbnb.com, Sept. 2016. Data processed by the author. than 3 housing units for rent can be observed, around 3 or 4 cases, showing how such activity is still just a supplement of income. Although no detailed data are available to verify the conformity between licensed accommodation facilities and those mentioned on the website, the difference among the number of listings (289) and that of licensed B\&Bs and vacation rentals (210) helps approximately estimate a 30 per cent supremacy of alternative accommodations. Furthermore, the website does not provide any subscription archive, therefore it is impossible to make comparisons between 2015 and 2016, however, the reference to The Floating Piers as part of the title of many announcements suggests, even in this case, the extent of the positive impulse that it gave to tourism as well. Eventually, also as regards Airbnb, there's a remarkable concentration of listings coming from the Brescia side of the lake, compared to the few accommodations on Bergamo side.

Through the analysis of the circumstances from each province, it is possible to highlight how the number of listings posted is higher than the amount of the actual licensed vacation rentals and $B \& B s$, except for Monte Isola and Marone, where the number of official structures, compared to Airbnb rentals, has respectively doubled and tripled. These data suggest the existence and persistence of a major tradition concerning touristic accommodation, featuring the traditional wordof-mouth communication channels, although the lack 
of data about it cannot confirm this assumption. Moreover, these data show how not all the licenced structures post announcements on the website. Generally, a comparison between the official data with the Airbnb ones helps point out what tends to be the case of touristic locations, stressing the potential of this new accommodation facility in places, like Iseo Lake, where very few hotel accommodations are situated.

From holiday house rentals to a scattered hospitality

Until now, while examining the situation of Iseo Lake, only those houses which are already part of the tourism market, officially or not, had been taken into account. However, based on the ISTAT data collected during the last census 2011, it is possible to notice the existence of numerous "unoccupied houses" within the G16 municipalities. Specifically, this term means an aggregate including vacation houses, lodgings occupied by nonresident people (like off-campus students, off-site workers) and empty residences. Since 2001, the census has not mentioned the building intended use anymore, making no reference to "vacation rentals" unlike the previous census, making it impossible to quantify rent-out buildings for tourist purposes.

This phenomenon affects the whole territory, as shown in Figure 3, and spreads differently within the district territories. The municipali-

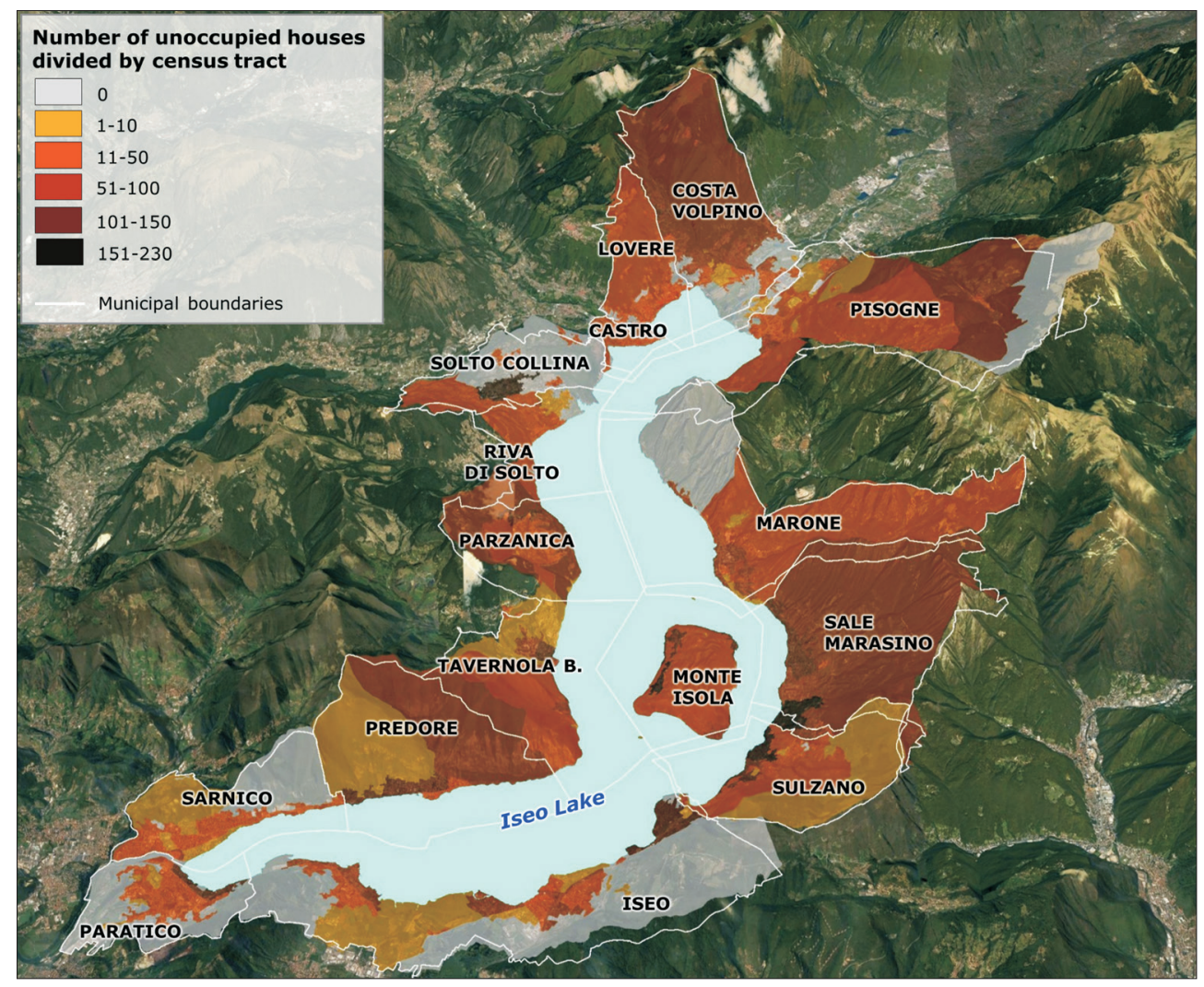

Fig. 3. Number of unoccupied houses broken down by census section within G16 municipalities. Data source: ISTAT Population and housing census, 2011. Data processed by the author. 
ties in the lower part of the lake are characterized by a concentration of unoccupied buildings especially in the historical centres and lakeshore. On the contrary, the municipalities in the upper part of the lake, particularly Costa Volpino and Pisogne, show a higher number of unoccupied mountain areas. Finally, in Sale Marasino unoccupied residences are copiously distributed across the whole territory.

Considering these data, out of a total of 33,700 residences notified by the ISTAT the unoccupied ones account for about 22 per cent of the whole (the buildings occupied at least by one person are 26,117 , while the unoccupied ones are 7,589) (ISTAT 2011). Although being in line with the national average, which is 23 per cent ${ }^{8}$, these data are relevant with special reference to the territorial distribution with a greater impact on mountain areas and historical centres, revealing a progressive abandonment of those areas towards more accessible places. As a result, the number of residents has decreased, employment in seasonal-only facilities, service reduction, and consequently, a drop of interest (Macchiavelli, A. 2011). The under-use of buildings, therefore, represents a problem for those places, but at the same time could lead to new types of tourism. As regards Iseo Lake, which became famous worldwide thanks to The Floating Piers event, the official ISTAT and Airbnb data show the proliferation of new reception accommodations, managed either entrepreneurially or not, supporting hotels during those 16 "Christo-dedicated" days and allowing them to face a huge accommodation demand. In view of the future promotion of sustainable tourism, the development of this new kind of "human-sized" accommodation managed by locals could become a distinctive trait of the lake territory.

\footnotetext{
${ }^{8}$ According to Italian Association of Private Construction Contractors (ANCE), the Italian housing stock mainly consists of lodgings occupied by residents, equal to 24 million units (77.3\% of the total), while 7 million units are unoccupied or occupied by nonresident people (ANCE 2015).
}

From new forms of "micro-accommodation" to territorial regeneration: inspiring experiences

In the 1980s, the concept of albergo diffuso was born for the first time to support the need to recover abandoned houses (and subsequently restructured) following the earthquake in the Friuli-Venezia Giulia region (Italy) in 1976. The albergo diffuso (AD), or "scattered hotel", is a form of hospitality characterised by host customers in the accommodations created inside and around the existing houses in mostly rural contexts, with a centralized reception and provided with all the assistance services that hotels should have (DALL'ArA, G. 2015).

According to a research by JFC consulting, this is one of the accommodation types preferred by the visitors to the villages $(19.2 \%$ versus $22.9 \%$ in farm holiday and $21.2 \%$ in B\&Bs), because it allows tourists to live in contact with residents and their traditions, emphasizing an ever-increasing search for authenticity on the tourists (JFC 2016).

In fact, the $\mathrm{AD}$ offers visitors the opportunity of "living in the area", by taking part in the social life of the village, and should prevent the depopulation of small rural towns. In Italy, there are about one hundred ADs and this model has been reproduced in several Countries worldwide, like Spain, Switzerland, Croatia, Germany, San Marino, Japan and China.

A case of positive scattered hospitality model is the historical village of Ornica, situated in northern Italy, in a valley of the Orobic Alps in the province of Bergamo. This initiative arose from the synergy between a contractor and a local women cooperative, Donne di montagna (www.albergodiffusoornica.it). The village was at risk of extinction and had only 160 inhabitants, while today, thanks to the involvement of the inhabitants, has tripled the presences in summer and is effective all year long9 9 . In addition to hospi-

\footnotetext{
${ }^{9}$ Val Brembana is the Lombard area that has suffered the greatest depopulation in the last 30 years and is now included in the PADIMA (Policies Against Depopulation In Mountain Areas) European project,
} 
tality, the village offers numerous experiences such as trekking, tastings, sheep shearing, cheese production, haymaking, harvesting of wild herbs, etc. (GANdolfi, A. 2017). At the same time, in recent years, Airbnb has shown a growing interest in rural areas and villages, funding numerous projects for the empowerment of small communities through the activation of tourist experiences.

Civita di Bagnoregio is a small village in the Province of Viterbo (Lazio) with only 6 residents in wintertime ${ }^{10}$. Here Airbnb, together with several partners and in COoperation with the municipality of Civita, has contributed to the restoration of Casa d'Artista (Home of the Artist), a historically significant building in the town, making it the first public listing available on the platform, whose profits will be used to fund cultural projects in Civita. In 2017, the Italian Villages Campaign ${ }^{11}$ was launched and sponsored by The National Association of Italian Municipalities (ANCI) in cooperation with the Italian Ministry of Culture and Tourism (MiBACT). It promotes more than 40 villages all over the country, thus developing a nationwide marketing campaign to help promote non-urban travels. In three of these towns (Lavenone in Lombardy, Civitacampomarano in Molise and Sambuca di Sicilia in Sicily) three public projects will be redeveloped in cooperation with local communities, as happened in the pilot project in Civita.

Eventually, Airbnb launched a Community Tourism Programme to support innovative

while the Donne di Montagna Cooperative has become a case study. In 2017, the guests registered at the hotel were, excluding children's workshops, more than 300, with a cost from 30 to 65 EUR per day (GAndolfi, A. 2017).

${ }_{10}$ The small village is set on the top of a tuff hill that is that is progressively collapsing, therefore Civita is known as "the dying city". It is connected to the surrounding countryside by a one-kilometre bridge suspended at a height of 70 metres.

${ }^{11}$ The campaign was launched on the occasion of The Year of Italian Villages 2017, sponsored by Italian Ministry of Culture and Tourism (MiBACT) (www. turismo.beniculturali.it). projects among local communities which encourage healthy tourism. In Italy, Matera has been awarded the 2019 European Capital of Culture. Several initiatives are planned to involve the local community and travellers; one of them is Wonder Grottole, a regeneration project regarding a small town $30 \mathrm{~km}$ away from Matera on the top of the Lucania hills, which has 300 inhabitants and 629 abandoned houses. Airbnb is selecting four people who will move to the small town for three months to become temporary citizens and volunteer for the local non-profit organisation called "Wonder Grottole" whose aim is to revitalize the city centre of the town. Other projects for small villages are developed in Spain, the European country with the highest number of empty houses, as well as in France, Ireland, Japan and other Countries (Airbnb 2017).

Although these projects have led to the renovation of a small number of buildings, they are still indicative of the potential offered by the Airbnb platform, as well as of the possibility of cooperating with the local administrations, with a view to regenerating small villages and reducing the concentration of tourists in the most famous locations. These opportunities could be fully exploited through the creation of a network of operators, communities and administrations working together in order to reduce the negative impacts of the spread of shortterm rentals, without, however, boycotting them. Probably, all these initiatives will help Airbnb prove its ethics but at the same time allow people to use one of the most famous digital rental platforms in the world become aware of new routes through small villages, while the experience of Ornica shows that another kind of tourism is possible.

\section{Conclusions}

With the regional tourism law no. 27/2015, Lombardy tried to apply the same financial, security, communication and guest notification rules to all the hotels and other collective 
accommodations, including non-enterprise managed vacation rentals (art. 26 of regional law no. 27/2015). Today, every owner is obligated to notify both his business start-up and guest identities to his/her municipality, including occasional lodgings ${ }^{12}$. Besides assuring a higher supervision, such legislation should allow for a greater accuracy for the collection of data, thus providing a realistic overview of tourism in Lombardy. However, it is necessary to evaluate the complications that the new law could entail for occasional landlords. If it is true, indeed, that the spread of the Internet has encouraged the development of new accommodation systems, it is also true that the owners are often old people, especially in the uphill areas, or city residents with a second home who may find it difficult to manage their apartments. At worst, this could work as a disincentive for these places, affecting the whole local development. In order to avoid such negative consequences, in the Lake Iseo area, the setting up of an entity, possibly led by the G16 association, should be pursued with a double purpose: supervising the territory and supporting the fulfilment of the new law regulation by the owners. Moreover, the promotion of a vacation lodgings network could promote the enhancement of the tourist facilities in the Lake Iseo, bettering its quality and facilitating the employment of unoccupied houses. Such entity, in addition to the assistance to the owners both through their business first steps and through the management of tourism flow notification, should entirely encourage the vacation lodging network through the www.iseolake.info website, regularly posting a list of accommodations and providing owners with information about Airbnb

\footnotetext{
${ }^{12}$ Based on art. 14 Lombardy Region, through the Regional Tourism Observatory, receives from each municipality the so-called SCIA (Verified business start-up notification) and the preventive start-up notifications of all the receptive structures (short rentals included), then posts them online (on the Regione Lombardia website) as a "unified regional list divided by typology", which is still a work in progress (rl 27/2015, art. 14).
}

and similar websites, in order to positively exploit this international showcase. This authority should also represent a reference point both for tenants who - against the payment of a yearly fee - will receive assistance, and for tourists, who will gain useful information in order to plan their own vacations.

An example of service entity of this kind can be found in another Italian Region: Trentino Alto-Adige, one of the most important tourist areas in the Alps which, in the 1970's, quickly developed this tourist apartments trend. In 2002, the Trento province administration issued the provincial law 07/2002 "Protocol of hotel and non-hotel accommodation facilities and quality promotion of touristic capacities" (art. 37bis), which imposed the touristic lodging notification to the municipality for any kind of accommodation for stays longer than 14 days staying even if not consecutive with the purpose of creating a location rent database. Moreover, a national and provincial tourist marketing society, Trentino Marketing, together with Territorial Tourism companies, activated a vacation housing enhancement project. This entailed the mapping, classification and certification of every lodge with the aim of reintegrating at least a part of those 125,000 unused sleeping accommodations into the tourist network. Thanks to a series of loans, provided by the Territorial Agreements, some of the above-mentioned apartments have been renovated to guarantee a good quality standard (ANDREOTTI, S. et al. 2011).

On the basis of this, and through the aid of the new regulations in Lombardy, the G16 association may create a register reporting all the operative vacation lodgings, managed both entrepreneurially or not, followed by the mapping and classification of unoccupied houses, verifying their state and the rental agreements. Based on this information, local administrations should start a process of community involvement from those places with a high concentration of unoccupied houses, going beyond the Trentino experience to support a "participative" tourism actually starting from the renovation of those 
structures. The development of this kind of "alternative" accommodations, managed by locals and close to the very nature of the place, could turn up as an opportunity for a tourist regeneration, turning the "scattered accommodation capacity" into the distinctive trait of Lake Iseo.

\section{REFERENCES}

Airbnb 2017. Beyond cities: How Airbnb supports rural revitalization. Available at: www.airbnbcitizen.com

ANCE 2015. Lo stock abitativo in Italia (The housing stock in Italy). Available at: www.ance.it/docs/docDownload.aspx?id=25011

Andreotti, S., Grigolli, P., Rigoni, E. and Sacco, F. 2011. Seconde case e appartamenti turistici, l'esperienza del Trentino (Second homes and tourist apartments, the experience of Trentino). In $L e$ abitazioni di vacanza nella funzione turistica territoriale. Diffusione, problematiche ed esperienze di gestione. Ed.: Macchiavelli, A., Milano, FrancoAngeli, 41-68.

Bálint, D. and TrócsánYI, A. 2017. New ways of mobility: the birth of ridesharing. A case study from Hungary. Hungarian Geographical Bulletin 65. (4): 391-405. Available at: https://doi.org/10.15201/ hungeobull.65.4.7

Bank of Italy 2017. Survey on Italy's International Tourism 2017. Available at: www.bancaditalia.it (in Italian)

BURINI, F. 2011. Scattered tourism: community mapping for the promotion of eco-museums. Paper presented at the $7^{\text {th }}$ Annual International Conference on Tourism, 13-16 June 2011, Athens, Greece, ATINER.

Dall'Ara, G. 2015. Manuale dell'Albergo Diffuso. L'idea, la gestione, il marketing dell'ospitalità diffusa (The Albergo Diffuso Manual. The idea, the management, the marketing of scattered hospitality). Milano, FrancoAngeli.

Federalberghi 2018. Turismo e shadow economy, tutela del consumatore, concorrenza leale ed equità fiscale al tempo del turismo 4.0 (Tourism and shadow economy, consumer protection, fair competition and fiscal equity at the tourism 4.0 time). Roma, Federalberghi. Available at: www.federalberghi.it.

Irimiás, A. and Michalkó, G. 2013. Religious tourism in Hungary - an integrative framework. Hungarian Geographical Bulletin 62. (2): 175-196.

ISTAT 2011. $15^{\text {th }}$ Population and housing census. Available at: http://dati-censimentopopolazione.istat.it (in Italian)

ISTAT 2017a. CAPI Trips and Holiday Survey. Available at: http://dati.istat.it/?lang=en\# (in Italian)

ISTAT 2017b. Capacity of Collective Accommodation Establishments and Occupancy in Collective Accommodation Establishments. Available at: http:// dati.istat.it/?lang=en\# (in Italian)
ISTAT 2017c. Capacity of Collective Accommodation. Available at: http://dati.istat.it/?lang=en\# (in Italian) JFC 2016. I piccoli Borghi Italiani - quando piccolo è bello (The small Italian villages - when small is beautiful). Available at: www.jfc.it

Kaplant, R.A. and Nadlert, M.L. 2015. Airbnb: A case study in occupancy, regulation and taxation. University of Chicago Law Review Online 82. (1): 103-115. Available at: https://chicagounbound. uchicago.edu/uclrev_online/vol82/iss1/7/

Karlsson, L. and Dolnicar, S. 2016. Someone's been sleeping in my bed. Annals of Tourism Research 58 . 156-170.

Macchiavelli, A. (ed.) 2011. Le abitazioni di vacanza nella funzione turistica territoriale. Diffusione, problematiche ed esperienze di gestione (Vacation homes in the territorial tourist function. Dissemination, problems and management experiences). Milano, FrancoAngeli.

Minuti, M.S. and Incipit Consulting 2016. Il sommerso turistico nella provincia di Bergamo. Il fenomeno degli affitti brevi ai turisti (The hidden tourism in the Province of Bergamo. The phenomenon of short rents for tourists). Paper presented at the meeting Il sommerso turistico nella provincia di Bergamo. Conoscere e contrastare l'abusivismo per promuovere l'accoglienza e il lavoro, July $19^{\text {th }}$ 2016. Bergamo, Ascom Confcommercio Bergamo.

Osкам, J. and Boswijk, A. 2016. Airbnb: the future of networked hospitality businesses. Journal of Tourism Futures 2. (1): 22-42. Available at: https://www.emeraldinsight.com/doi/full/10.1108/JTF-11-2015-0048

Rátz, T., Kundi, V. and Michalkó, G. 2015. The hidden dimensions of cultural consumption within the framework of tourism mobility. In Touring Consumption. Eds.: SonnenburG, S. and Wee, D., Wiesbaden, Springer VS. 285-302.

Richardson, L. 2015. Performing the sharing economy. Geoforum 67. 121-129.

Romita, T. 2010. Il turismo residenziale in Italia: un fenomeno sociale diffuso e fai da te. (The residential tourism in Italy: a widespread and do-it-yourself social phenomenon). In Il turismo residenziale. Nuovi stili di vita e di residenzialità, governance del territorio e sviluppo sostenibile in Europa. Ed.: Romita, T., Milano, FrancoAngeli, 35-66.

Zervas, G., Proserpio, D. and Byers, J.W. 2017. The rise of the sharing economy: estimating the impact of Airbnb on the hotel industry. Journal of Marketing Research 54. (October): 687-705.

Newspapers:

Gandolfi, A. (03/12/2017). Ornica, il borgo bergamasco salvato dalle donne delle montagne (Ornica, the bergamo village saved by the mountain 
women). Corriere della Sera. Available at: www. corriere.it/buone-notizie/17_dicembre_03/ornica-borgo-bergamasco-salvato-donne-montagneapple-0c2cca68-d832-11e7-83d0-5335217d8231. shtml?refresh_ce-cp\#

Burgen, S. (02/06/2017). Barcelona cracks down on Airbnb rentals with illegal apartment squads. The Guardian. Available at: www.theguardian.com/ technology/2017/jun/02/airbnb-faces-crackdownon-illegal-apartment-rentals-in-barcelona
Kendal, M. (18/09/2016). Airbnb fights unfriendly regulations with wave of lawsuits against San Francisco, other cities. The Mercury News. Available at: www. mercurynews.com/2016/09/18/airbnb-fights-unfriendly-regulations-wave-lawsuits-san-francisco/

Oltermann, B. (08/06/2016). Berlin ban on Airbnb short-term rentals upheld by city court. The Guardian. Available at: www.theguardian.com/ technology/2016/jun/08/berlin-ban-airbnb-shortterm-rentals-upheld-city-court 
